\title{
Comparative study of Japanese frozen elephant trunk device for open aortic arch repairs
}

Hitoshi Ogino, MD, PhD, ${ }^{\mathrm{a}}$ Yutaka Okita, MD, PhD, ${ }^{\mathrm{b}}$ Naomichi Uchida, MD, PhD, ${ }^{\mathrm{c}}$ Masaaki Kato, MD, PhD, ${ }^{\mathrm{d}}$ Shinji Miyamoto, MD, PhD, ${ }^{\mathrm{e}}$ Hitoshi Matsuda, $\mathrm{MD}, \mathrm{PhD},{ }^{\mathrm{f}}$ and Michikazu Nakai, $\mathrm{PhD},{ }^{\mathrm{g}} \mathrm{J}$-Open Cardiac Aortic Arch Disease Replacement Surgical Therapy Study Investigators*

\section{ABSTRACT}

Objective: We performed a multicenter prospective comparative study to determine the impact of a Japanese frozen elephant trunk device on total arch replacement compared with conventional repair without it.

Methods: Between 2016 and 2019, a total of 684 patients (frozen elephant trunk procedure; $n=369$; conventional repair, $n=315$ ) from 41 institutions were enrolled. The 2 procedures were selected according to each center's strategy.

Results: The frozen elephant trunk procedure was applied more for aortic dissection, whereas the conventional repairs were predominantly performed for aneurysms. In the former, only hypothermic circulatory arrest time was reduced among the intraoperative parameters. Although there were no differences in the 30-day and in-hospital mortality rates ( $0.8 \%$ and $1.6 \%$, respectively, for the frozen elephant trunk procedure vs $0.3 \%$ and $0.6 \%$, respectively, for conventional repair), the neurologic complication rates were significantly higher in stroke $(5.7 \%$ vs $2.2 \% ; P=.022)$ and paraplegia $(1.6 \%$ vs $\circ \% ; P=.023)$. In the propensity score matching analyses using 11 variables, statistical significance disappeared in the differences for mortality and neurologic morbidity (stroke and paraplegia/paraparesis) rates of 194 patients of each group, although they were still higher for the frozen elephant trunk procedure.

Conclusions: The early outcomes of total arch replacement with the frozen elephant trunk procedure were acceptable despite its higher prevalence of emergency or redo surgery, which was comparable to that of the conventional repair. This procedure had higher rates of spinal cord injury than the conventional repair, which is a disadvantage of this approach. (J Thorac Cardiovasc Surg 2022;164:168192)

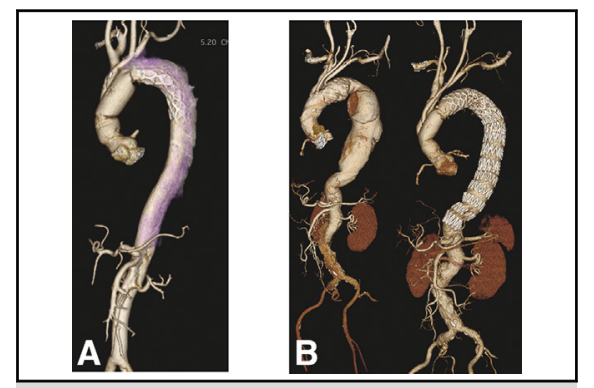

A, TAR with FET for AD. B, Staged repairs of that followed by endografting.

CENTRAL MESSAGE

Total arch repair using a Japanese FET

provides acceptable early outcome.

Compared with the conventional

procedure, the higher rate of $\mathrm{SCl}$ is a

disadvantage of this approach.

\section{PERSPECTIVE}

Open arch repairs with a Japanese FET device yields acceptable early outcome with low mortality and morbidity rates even in emergency or redo surgery. This approach is expected to have an impact on the late outcomes by providing aortic remodeling of the downstream dissecting aorta or shrinkage of aneurysm and avoiding aortic events including secondary open or endovascular intervention.

See Commentaries on pages 1693,1694 , and 1696
From the a Department of Cardiovascular Surgery, Tokyo Medical University, Tokyo, Japan; ${ }^{b}$ Cardioaortic Center, Takatsuki General (former: Kobe University), Osaka, Japan; ' Department of Cardiovascular Surgery, Yao Tokushukai Hospital, Osaka, Japan; ${ }^{\mathrm{d}}$ Department of Cardiovascular Surgery, Morinomiya Hospital, Osaka, Japan; ${ }^{\mathrm{e}}$ Department of Cardiovascular Surgery, Oita University, Oita, Japan; ${ }^{\mathrm{f}}$ Department of Vascular Surgery, and ${ }^{\mathrm{g}}$ Center for Cerebral and Cardiovascular Disease Information, National Cerebral and Cardiovascular Center, Osaka, Japan; ${ }^{\mathrm{h}}$ Department of Cardiovascular Surgery, Kishiwada Tokushukai Hospital, Osaka, Japan; ${ }^{\mathrm{i}}$ Department of Cardiovascular Surgery, Nara Prefecture General Medical Center (former: Tenri Hospital), Nara, Japan; ${ }^{j}$ Department of Cardiovascular Surgery, Hanaoka Seishu Memorial Hospital (former: Hokkaido University), Hokkaido, Japan; ${ }^{\mathrm{k}}$ Department of Cardiovascular Surgery, Kyoto University, Kyoto, Japan; ${ }^{\text {DDepart- }}$ ment of Cardiovascular Surgery, Keio University, Tokyo, Japan; ${ }^{\mathrm{m}}$ First Department of Surgery, Hamamatsu University School of Medicine, Shizuoka, Japan; ${ }^{\text {n}}$ Department of Cardiovascular Surgery, Tohoku University, Miyagi, Japan; ${ }^{\circ}$ Department of Cardiovascular Surgery, Kobe University, Hyogo, Japan.

This study was carried out with support of Japan Lifeline Co, Ltd.

Number and date of Institutional Review Board approval: No. 1853 on May 16, 2016, by the ethical committees of Kobe University.

* J-Open Cardiac Aortic Arch Disease Replacement Surgical Therapy (J-ORCHESTRA) study investigators: Shinichi Higashiue, $\mathrm{MD}, \mathrm{PhD}$, Department of Cardiovascular Surgery, Kishiwada Tokushukai Hospital, Osaka, Japan; Kazuo Yamanaka, MD, PhD,
Department of Cardiovascular Surgery, Nara Prefecture General Medical Center (former: Tenri Hospital), Nara, Japan; Yoshiro Matsui, MD, PhD, Department of Cardiovascular Surgery, Hanaoka Seishu Memorial Hospital (former: Hokkaido University), Hokkaido, Japan; Kenji Minatoya, MD, PhD, Department of Cardiovascular Surgery, Kyoto University, Kyoto, Japan; Hideyuki Shimizu, MD, PhD, Department of Cardiovascular Surgery, Keio University, Tokyo, Japan; Norihiko Shiya, MD, $\mathrm{PhD}$, First Department of Surgery, Hamamatsu University School of Medicine, Shizuoka, Japan; Yoshikatsu Saiki, MD, PhD, Department of Cardiovascular Surgery, Tohoku University, Miyagi, Japan; and Kenji Okada, MD, PhD, Department of Cardiovascular Surgery, Kobe University, Hyogo, Japan.

Accepted for the 100th Annual Meeting of The American Association for Thoracic Surgery.

Received for publication June 22, 2020; revisions received March 15, 2021; accepted for publication March 17, 2021; available ahead of print April 1, 2021.

Address for reprints: Hitoshi Ogino, MD, PhD, Department of Cardiovascular Surgery, Tokyo Medical University, Tokyo, Japan 6-1-1 Nishishinjuku Shinjuku-ku Tokyo 160-0023 Japan (E-mail: hogino@tokyo-med.ac.jp). 0022-5223

Copyright $@ 2021$ The Authors. Published by Elsevier Inc. on behalf of The American Association for Pediatric Ophthalmology and Strabismus. This is an open access article under the CC BY-NC-ND license (http://creativecommons.org/licenses/by-nc-nd/4.0/). https://doi.org/10.1016/j.jtcvs.2021.03.079 


$\begin{array}{ll}\text { Abbreviations and } & \text { Acronyms } \\ \text { AD } & =\text { aortic dissection } \\ \text { CSFD } & =\text { cerebrospinal fluid drainage } \\ \text { cTAR } & =\text { conventional total arch } \\ & \text { replacement } \\ \text { ET } & =\text { elephant trunk } \\ \text { FET } & =\text { frozen elephant trunk } \\ \text { HCA } & =\text { hypothermia circulatory arrest } \\ \text { JCVSD } & =\text { Japan Adult Cardiovascular } \\ & \text { Surgery Database } \\ \text { J-ORCHESTRA }= & \text { J-Open Cardiac Aortic Arch } \\ & \text { Disease Replacement Surgical } \\ & \text { Therapy } \\ \text { LSCA } & =\text { left subclavian artery } \\ \text { PSM } & =\text { propensity score matching } \\ \text { RCP } & =\text { retrograde cerebral perfusion } \\ \text { SCI } & =\text { spinal cord injury } \\ \text { SCP } & =\text { selective cerebral perfusion } \\ \text { TAR } & =\text { total arch replacement } \\ \text { TARFET } & =\text { total arch replacement with FET }\end{array}$

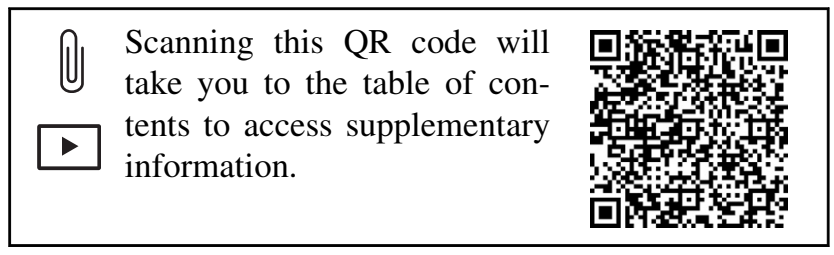

In 1983, Borst and colleagues ${ }^{1}$ developed a novel concept of the elephant trunk (ET) procedure for extensive aortic replacement. In 2003, a similar technique using ET with a stent referred to the frozen ET (FET) was reported by the same Hanover group. ${ }^{2}$ Since then, as a new trend of thoracic aortic surgery emerged with commercially available devices from Europe and China, the FET procedure frequently has been applied to open arch repairs for aortic dissection (AD) and aneurysms. ${ }^{3-13}$ The current application of FET is for 1-stage exclusion of an arch aneurysm or for dilatation of the true lumen and early closure of the false one (aortic remodeling) with inside reinforcement of the dissecting aortic stump in $\mathrm{AD}$. On the other hand, in Japan, Kato and colleagues ${ }^{14}$ initiated a new graft-implanting method, known as the "open stent graft," similar to the FET procedure in the mid-1990s. Since then, some drawbacks and benefits of FET procedures have been discussed. ${ }^{15-19}$ In 2014, a new FET device, the J Graft Open Stent Graft, renamed the "J Graft FROZENIX" in 2016 (Japan Lifeline Co, Tokyo, Japan) (Figure 1), became commercially available. ${ }^{20}$ Through the clinical uses of this FET device, a prospective comparative study, the J-Open Cardiac Aortic Arch Disease Replacement Surgical Therapy (J-ORCHESTRA) study, was conducted to determine its impact on the outcome of total arch replacement (TAR), comparing the early outcome between TAR with FET (TARFET) and conventional TAR (cTAR).

\section{PATIENTS AND METHODS \\ Study Design}

The J-ORCHESTRA study is a multicenter prospective comparative investigation and was approved by the ethical committees of Kobe University (No.1853, May 16, 2016) and by the 40 other participating institutions.

\section{Patients}

Between 2016 and 2019, a total of 684 patients from 41 institutions were enrolled (Table E1). For patient safety, indications for TARFET were variable, depending on each patient's aortic pathology and other conditions, as well as each center's surgical strategy (Figures E1 and E2). TARFET was performed in 369 patients, and cTAR was performed in 315 patients (Table 1). In 146 patients (46.2\%) undergoing cTAR, conventional ET was applied for inside reinforcement of the distal aortic stump, ${ }^{21,22}$ for making the anastomosis or landing site for further open surgery or endografting, ${ }_{1}^{1}$ or for early closure of false lumen of the descending aorta in $\mathrm{AD}$ (Table 2). ${ }^{23,24}$ Both procedures were performed for selected 85 patients having type $\mathrm{B} \mathrm{AD}$ combined with arch aneurysm.

\section{Surgical Procedures}

The aortic arch was approached through a median sternotomy, and cardiopulmonary bypass was established with the usual fashion. Patients were cooled down to a bladder or rectal temperature of $20^{\circ} \mathrm{C}$ to $30^{\circ} \mathrm{C}$. After cooling, hypothermic circulatory arrest (HCA) was started and cardioplegic arrest was induced. The transverse arch was opened. For brain protection, antegrade selective cerebral perfusion (SCP) was used in the majority of the patients. ${ }^{25-27}$ The arterial pressure was maintained in the range of 30 to $50 \mathrm{~mm} \mathrm{Hg}$ with flows of 10 to $12 \mathrm{~mL} / \mathrm{kg} / \mathrm{min}$. In less than $20 \%$, retrograde cerebral perfusion (RCP) through the $\mathrm{SVC}$ at $18^{\circ} \mathrm{C}$ was maintained at the jugular pressure of $15 \mathrm{~mm} \mathrm{Hg}{ }^{28}$ In RCP, arch-vessel reconstruction was performed first to reduce the RCP time.

\section{Conventional Total Arch Replacement}

In aneurysms, the descending aorta distal to the aneurysm was transected. ${ }^{21,22,25-27}$ Open distal anastomosis using a multibranched arch Dacron graft was performed with the corporeal HCA. In $\mathrm{AD}$, the descending aorta was transected distal to the left subclavian artery (LSCA). ${ }^{21-27}$ In 31 cases $(50.8 \%)$, the distal anastomosis was made using the ET for inside reinforcement and early closure of false lumen of the descending aorta. ${ }^{23,24}$ The ET was also used as the anastomosis or landing site for further open surgery or endografting for a downstream extended aortic lesion. ${ }^{1}$

\section{Total Arch Replacement With Frozen Elephant Trunk}

TARFET was performed for 1-stage exclusion of an arch aneurysm with downstream extension or for dilatation of the true lumen and early closure of the false one (aortic remodeling) with inside reinforcement of the dissecting aortic stump in AD. According to each center's protocol, the distal aortic anastomoses were made at various portions of zones 0 to 3 . A FET device, in variations of 17 to $39 \mathrm{~mm}$ in diameter and $6,9,12$, or $15 \mathrm{~cm}$ in length, was selected depending on each surgical strategy (Figure 2). In some centers, retrograde femoral artery perfusion was added during the FET deployment to avoid distal embolization causing spinal cord injury (SCI). ${ }^{20,29}$ The proximal part of FET was fixed to the aortic stump, to which another multibranched arch graft was anastomosed. 

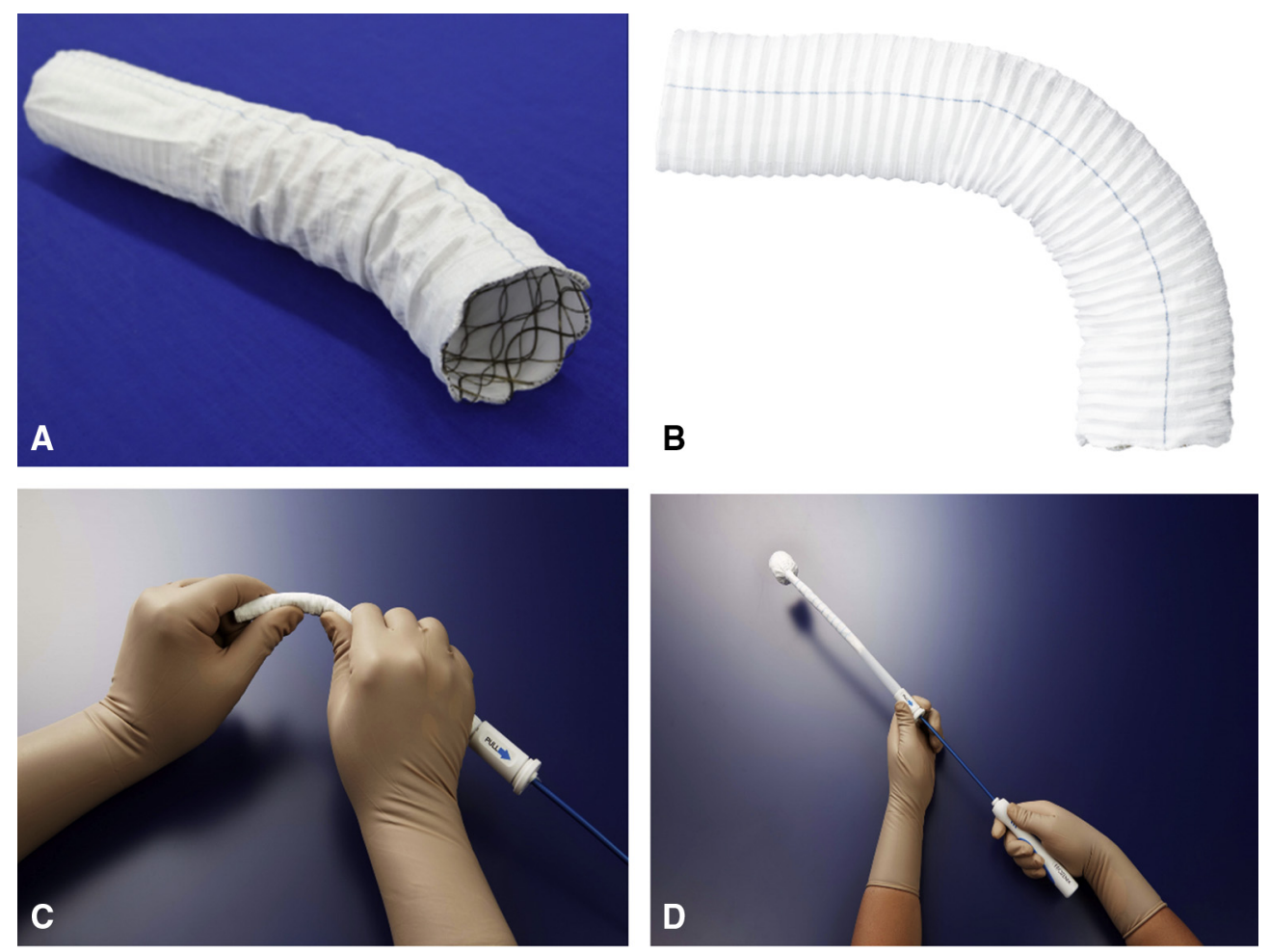

FIGURE 1. J Graft FROZENIX (Japan Lifeline Co, Tokyo, Japan). A and B, The FET consists of 2 parts of the graft part and the stent part. The graft part is a polyester woven Dacron graft with permeability of less than $500 \mathrm{~mL} / \mathrm{cm}^{2} / \mathrm{min}$ (at $120 \mathrm{~mm} \mathrm{Hg}$, and in water at $37^{\circ} \mathrm{C}$ ) and a thickness of $450 \mu \mathrm{m}$. The stent part has a woven structure made of Nitinol wire, a super-elastic/shape-memory alloy. The stent part is fixed to the inside of the graft to protect the stent part from directly coming in contact with the vessel wall. $\mathrm{C}$ and $\mathrm{D}$, The stent part also has a structure such that its wire top hardly protrudes inward when the device is bent. The delivery system consists of 2 elements: the resin shaft and soft sheath.

In both procedures, the systemic circulation was restarted after the distal aortic anastomosis using a side arm of the graft. In some centers, the proximal aortic anastomosis was conducted first, whereas the arch vessels were reconstructed first in others. ${ }^{21-27}$

\section{Frozen Elephant Trunk Device}

The FET device consists of a polyester woven Dacron graft and a woven-structured internal stent made of Nitinol wire (Figure 1). ${ }^{20}$ The delivery system has a resin shaft and a soft sheath. The former is equipped with a metal core rod that enables the bending of the tip. Four variations of the FET length are available $(6,9,12$, and $15 \mathrm{~cm})$. The outer diameters of FET range from 17 to $39 \mathrm{~mm}$ in 2-mm increments. The actual procedures of FET placement are described as follows: (1) bending of the distal FET tip fitted to the curved arch to descending aortic shape; (2) insertion of the FET into the descending aorta using a guidewire, transesophageal echocardiography, or endoscopy; (3) adjustment of the marked proximal end of the FET stented part slightly down to the edge of the transected aortic stump; and (4) removal of the soft sheath for stent expansion to fix the FET to the target site.

The FET length and diameter were decided according to the surgical strategy of each institute, referring to the proceeding clinical trial. ${ }^{20}$ Generally, a FET device of $10 \%$ to $20 \%$ oversize in aneurysm and one of size $80 \%$ to $90 \%$ of the diameter of the descending aorta in $\mathrm{AD}$ are recommended.

\section{End Points}

The end points were compared between the TARFET and cTAR procedures. As the primary end point, 30-day and in-hospital mortalities were determined. As the secondary end points, the application of TARFET procedure, surgical parameters, and incidence of major complications were revealed. The surgical parameters included time of operation, cardiopulmonary bypass, myocardial ischemia, SCP, corporeal HCA, and duration of intensive care unit or hospital stays. Various morbidities were defined as follows. ${ }^{30,31}$ Temporary neurologic dysfunctions included severe delirium, confusion, agitation, and memory disturbance, all of which disappeared before discharge. Permanent neurologic dysfunctions (ie, stroke) were persisting brain dysfunctions at discharge with new postoperative lesions on computed tomography scans or magnetic resonance imaging. SCI consisted of paraplegia and paraparesis, including bladder-rectal disorders. Cardiac complications included perioperative myocardial infarction and low cardiac output defined as the statue requiring intra-aortic balloon pumping or administration of norepinephrine or epinephrine with greater than $0.1 \mathrm{r} / \mathrm{kg} / \mathrm{min}$. Respiratory failure was diagnosed when the patients required prolonged ventilation longer than 3 days, reintubation, or tracheotomy. Acute renal failure was defined as serum creatinine level increases to $2.0 \mathrm{mg} / \mathrm{dL}$ in patients with preoperative creatinine levels less than $1.0 \mathrm{mg} / \mathrm{dL}$, elevated more than $100 \%$ of the preoperative level in patients with high creatinine more than $1.0 \mathrm{mg} / \mathrm{dL}$, or requiring hemodialysis. Bleeding was defined as a complication for which a total blood transfusion of more than $5000 \mathrm{~mL}$ or platelet transfusion of more than 40 units was required, including reentry for bleeding. Complications of infection included severe wound infection, such as mediastinitis and graft infection, or sepsis.

\section{Data Collection}

The data were obtained in each hospital to fulfill case report forms. All data were transferred to Kobe University and analyzed independently by a biostatistician (M.N.) at the National Cerebral and Cardiovascular Center. 
TABLE 1. Patient characteristics

\begin{tabular}{|c|c|c|c|c|c|c|c|}
\hline \multirow[b]{2}{*}{ Preoperative variables } & \multicolumn{3}{|c|}{ Unadjusted dataset } & \multicolumn{3}{|c|}{ PSM adjusted dataset (1-11 variable) } & \multirow[b]{2}{*}{ SMD } \\
\hline & TARFET $(n=369)$ & cTAR $(n=315)$ & $P$ & TARFET $(n=194)$ & cTAR $(n=194)$ & $P$ & \\
\hline 1. Age, $y$, mean $\pm S D$ & $66.3 \pm 11.2$ & $70.0 \pm 12.2$ & $<.001 *$ & $68.9 \pm 10.7$ & $68.4 \pm 12.5$ & .691 & 0.04 \\
\hline Male gender, $\mathrm{n}(\%)$ & $280(75.9)$ & $237(75.2)$ & .850 & $137(77.8)$ & $144(74.2)$ & .405 & 0.08 \\
\hline \multicolumn{8}{|l|}{ Aortic pathology } \\
\hline Aneurysms, n (\%) & $129(35.1)$ & $224(70.9)$ & $<.001 *$ & $116(57.3)$ & $117(60.3)$ & .917 & 0.01 \\
\hline Nonruptured, n (\%) & $117(90.7)$ & $211(94.2)$ & .217 & $3(2.6)$ & $2(1.7)$ & .898 & 0.05 \\
\hline 2. Ruptured, n (\%) & $9(7.0)$ & $8(3.6)$ & .150 & $5(4.3)$ & $5(4.3)$ & & \\
\hline Impending ruptured, n (\%) & $3(2.3)$ & $5(2.2)$ & .955 & $108(93.1)$ & $110(94.0)$ & & \\
\hline 3. Dissections, n (\%) & $240(65.0)$ & $91(28.9)$ & $<.001 *$ & $78(40.2)$ & 77 (39.7) & .917 & 0.01 \\
\hline 4. Acute, n (\%) & $154(64.2)$ & $60(65.9)$ & .764 & $44(56.4)$ & $48(62.3)$ & .453 & 0.04 \\
\hline Subacute/chronic, $\mathrm{n}(\%)$ & $86(35.8)$ & $31(34.1)$ & .906 & $34(43.6)$ & $29(37.7)$ & & \\
\hline 5. Emergency/urgent, n (\%) & $146 / 17$ (44.2 of all) & $70 / 22(29.2$ of all $)$ & $<.001 *$ & $46 / 13$ (30.4 of all) & $47 / 6(27.3$ of all $)$ & .257 & 0.01 \\
\hline $\begin{array}{l}\text { 6. Redo, n }(\%) \\
\text { Preoperative status/coexisting }\end{array}$ & 31 (8.4 of all) & 14 (4.4 of all) & $.037^{*}$ & $13(6.7)$ & $12(6.2)$ & .836 & 0.02 \\
\hline 7. Shock, n (\%) & $24(6.5)$ & $12(3.8)$ & .116 & $7(3.6)$ & $9(4.6)$ & .610 & 0.05 \\
\hline 8. Cerebrovascular disease, $\mathrm{n}(\%)$ & $28(7.6)$ & $36(11.4)$ & .086 & $15(7.7)$ & $15(7.7)$ & 1.00 & 0.00 \\
\hline 9. CKD, n (\%) & $116(31.4)$ & $106(33.7)$ & .538 & $62(32.0)$ & $57(29.4)$ & .582 & 0.05 \\
\hline Hemodialysis, $\mathrm{n}(\%)$ & $10(2.7)$ & $7(2.2)$ & .683 & $3(1.6)$ & $3(1.6)$ & 1.00 & 0.00 \\
\hline Coronary artery disease, $\mathrm{n}(\%)$ & $26(7.1)$ & $45(14.3)$ & $.002 *$ & $17(8.8)$ & $23(11.9)$ & .316 & 0.10 \\
\hline Post-PCI, n (\%) & $19(5.2)$ & $28(8.9)$ & .076 & $16(8.3)$ & $15(7.7)$ & .817 & 0.05 \\
\hline 10. COPD, n (\%) & $58(15.8)$ & $67(21.3)$ & .063 & $32(16.5)$ & $24(15.1)$ & .248 & 0.11 \\
\hline 11. Japan score, Mean \pm SD & $10.07 \pm 9.10$ & $7.57 \pm 7.30$ & $<.001^{*}$ & $8.17 \pm 7.07$ & $7.90 \pm 8.04$ & .73 & 0.03 \\
\hline
\end{tabular}

PSM, Propensity score matching; TARFET, total arch replacement with frozen elephant trunk; $C T A R$, conventional TAR; $S M D$, standardized mean difference; SD, standard deviation; $C K D$, chronic kidney disease; $P C I$, percutaneous coronary intervention; $C O P D$, chronic obstructive pulmonary disease. *Significantly different.

\section{Statistics}

Categorical variables were compared via chi-square or Fisher exact test depending on size $(>5)$. Continuous variables were compared via the $t$ test or Mann-Whitney depending on normality, which was determined via the Shapiro-Wilk test. They are presented throughout as mean (standard deviation) or median (interquartile range). Propensity score matching (PSM) was performed using nearest neighbor matching constructed by a logistic regression model that adjusted for 11 variables in the overall cohort analysis and in subanalysis for acute AD and 10 variables for aneurysm. For all 3 PSM analyses, matching was performed in a 1:1 ratio without replacement using a caliper width of 0.25 multiplied by the standard deviation of the propensity score. Matching success was determined with none or at most 1 variable of an absolute standardized mean difference more than 0.1. Because of the extensive outcomes considered, Bonferroni correction was applied and a $P$ value of $.05 / 3=.017$ was deemed significant for brain/spinal cord variables. Missing data were found in the following variables: Japan score $(\mathrm{n}=64,9.36 \%)$ and chronic obstructive pulmonary disorder $(n=1,0.15 \%)$. If patients had missing data, their Japan scores and chronic obstructive pulmonary disorder frequency were not included in the unadjusted analyses and PSM analyses were performed with the complete datasets. Thus, a total of 65 patients were removed from the overall cohort analyses, 17 patients were removed from the acute $\mathrm{AD}$ analyses, and 43 patients were removed from the aneurysm analyses. Univariate and multivariable logistic regression analyses were performed to clarify independent risk factors for SCI. All statistical analyses were performed with JMP 13 programs (SAS Institute Inc, Cary, NC) and STATA 16.1 (StataCorp, LLC, College Station, Tex). Figures 2, E1, and E2 were made using Excel (Microsoft Corp, Redmond, Wash).

\section{RESULTS}

\section{Demographics}

The surgical outcomes of 369 patients with TARFET and 315 patients with cTAR were compared (Table 1). The patients with TARFET were younger. AD was predominant $(65.0 \%)$ in TARFET, whereas a higher incidence of aneurysm $(70.9 \%)$ was observed in cTAR. However, there were no differences in the prevalence of each category in both aortic pathologies. The incidences of emergency or urgent $(P<.001)$ and redo $(P=.037)$ surgeries were significantly higher in TARFET. Perioperative cerebrospinal fluid drainage (CSFD) was not routinely performed and was applied for 7 TARFET patients (acute AD in 4 and aneurysm in 3) and for 1 cTAR patient with aneurysm.

\section{Primary End Point}

The 30-day mortality rate was $0.8 \%$ for TARFET and $0.3 \%$ for cTAR $(P=.40)$, and the in-hospital mortality rate was $1.6 \%$ and $0.6 \%(P=.23)$ (Table 2$)$.

\section{Secondary End Points}

Clinical application of the total arch replacement with frozen elephant trunk. TARFET was applied for aneurysms in 129 patients and for AD in 240 patients (type A $[\mathrm{n}=178]$ and type B [62]), including 154 acute and 14 
TABLE 2. Surgical parameters and outcome

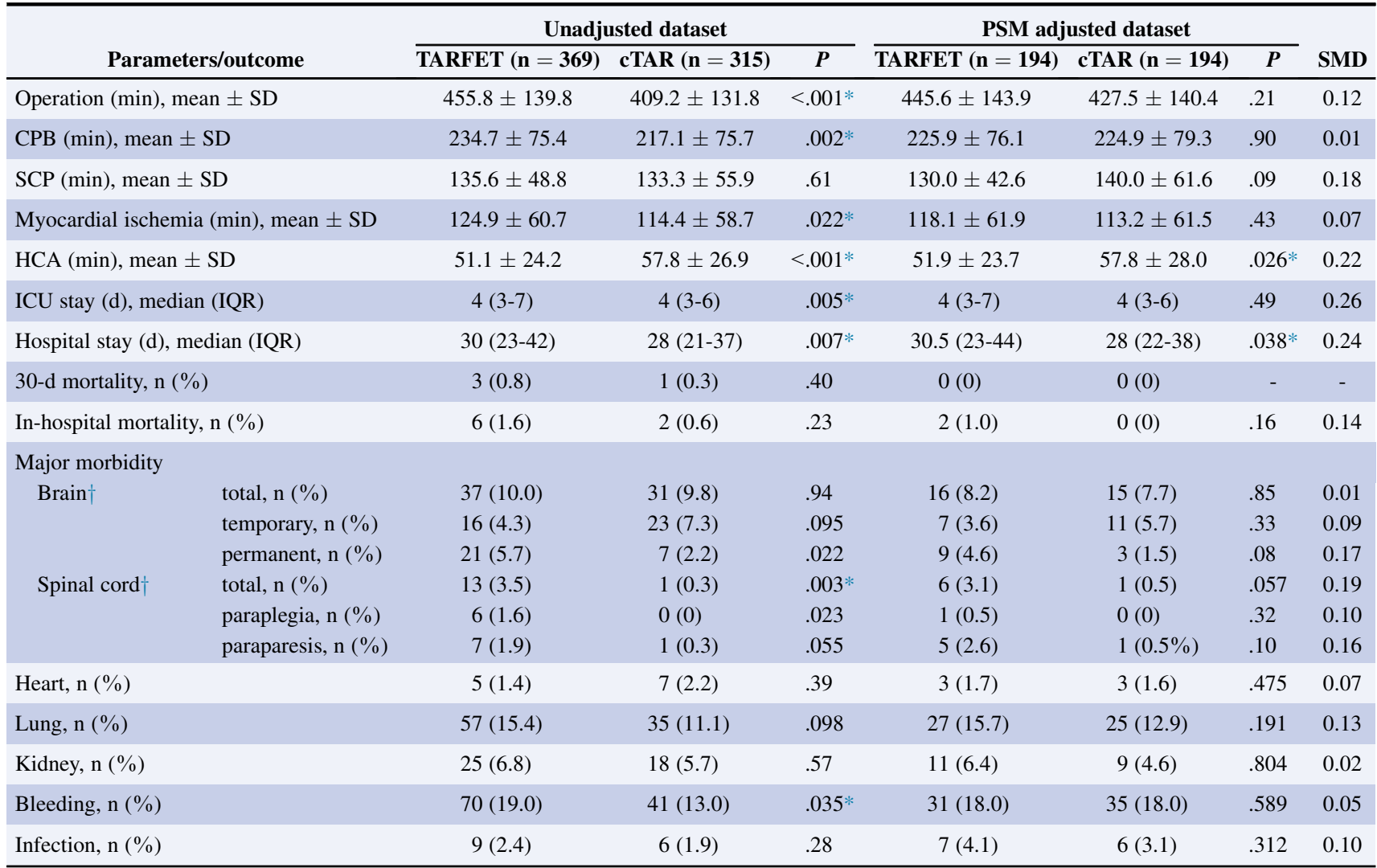

PSM, Propensity score matching; TARFET, total arch replacement with frozen elephant trunk; $c T A R$, conventional TAR; $S M D$, standardized mean difference; $S D$, standard deviation; $C P B$, cardiopulmonary bypass; $S C P$, selective cerebral perfusion; $H C A$, hypothermic circulatory arrest; $I C U$, intensive care unit; $I Q R$, interquartile range. *Significantly different. $\dagger$ Bonferroni correction was applied.

subacute ADs. cTAR was applied for aneurysms in 224 patients and for $\mathrm{AD}$ in 91 patients (type $\mathrm{A}[\mathrm{n}=78]$ and type $\mathrm{B}$ [13]), including 60 acute ADs (Table 1 and Figure E2). Regarding the size of FET devices and the level of its distal end, the majorities were 9 and $12 \mathrm{~cm}$ in length and 25, 27, and $29 \mathrm{~mm}$ in diameter (Figure 2, A). The landing levels of the FET distal end were almost above the T8 level, except for 7 patients: T9 in 6 and T12 in 1 (Figure 2, B).

Surgical parameters. In TARFET, the HCA time was significantly reduced $(P<.001)$, whereas the durations of other parameters were rather longer (Table 2).

Major complications. In TARFET, neurologic complication rates were higher: $5.7 \%$ versus $2.2 \%$ in brain permanent (stroke) and $1.6 \%$ versus $0 \%$ in paraplegia (Table 2). There were no significant differences in the other complications, except for the incidence of bleeding. No events related directly to the FET device such as stenosis or kinking occurred.

Propensity score matching analysis. PSM on 11 variables yielded matched cohorts with 194 patients in each group. In the PSM analysis, there were no significant differences in the mortality rates, with a 30 -day mortality rate of $0 \%$ for TARFET and $0 \%$ for cTAR and an in-hospital mortality rate of $1.2 \%$ and $0.6 \%(P=.56)$. Neurologic complications occurred more frequently in TARFET: $4.1 \%$ and $1.2 \%$ in stroke $(P=.09)$ and $1.2 \% / 2.9 \%$ and $0 \% / 0.6 \%$ in paraplegia/paraparesis $(P=.16 / 0.10)$. The HCA time was reduced for TARFET $(P<.001)$ (Tables 1 and 2$)$. However, the durations of other parameters were longer.

Comparison for acute aortic dissection. There were no significant differences in the preoperative settings, except for the rate of other malperfusion excluding the brain and coronary artery (Table 3 ). There were no differences in the mortality rates, with a 30-day mortality rate of $1.3 \%$ for TARFET and $0 \%$ for cTAR $(P=.38)$ and an inhospital mortality rate of $1.9 \%$ and $0 \%(P=.28)$. Despite no significant differences, the incidences of neurologic sequelae were higher for TARFET: $7.8 \%$ and $1.7 \%$ in stroke $(P=.092)$ and $2.6 \% / 1.3 \%$ and $0 \% / 0 \%$ in paraplegia/paraparesis $(P=.21 / 0.38)$. The HCA time was significantly shorter for TARFET. In the PSM analysis, similar findings with smaller differences were observed.

Comparison for aneurysm. There were no differences in the mortality rates, with a 30 -day mortality rate of $0.8 \%$ for TARFET and $0.4 \%$ for cTAR $(P=.69)$ and an in-hospital mortality rate of $1.6 \%$ and $0.9 \%(P=.57)$ (Table 4$)$. The incidences of neurologic complications were higher for TARFET: $5.4 \%$ and $2.2 \%$ in stroke $(P=.11)$, and $1.6 \% /$ 

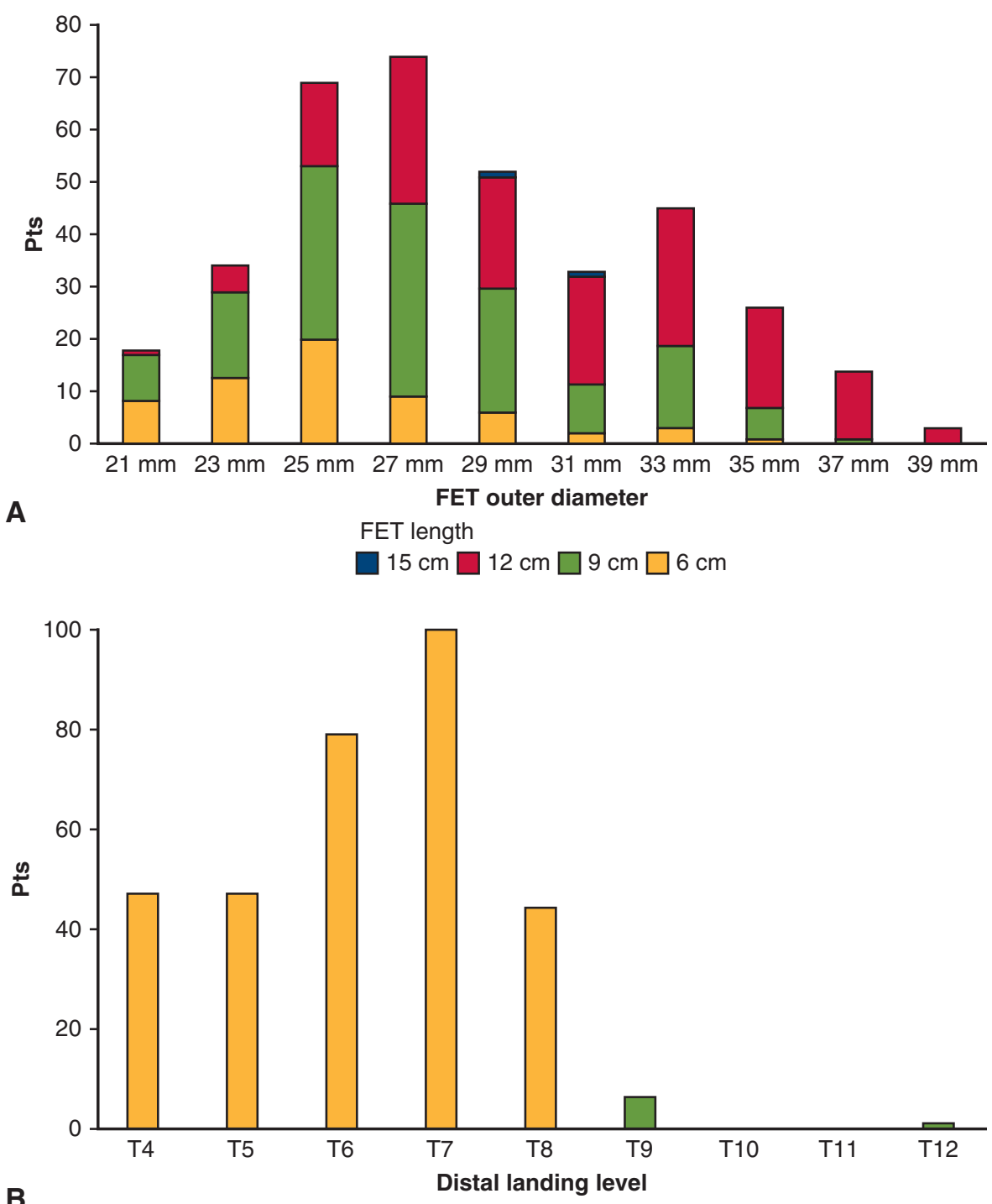

FIGURE 2. A, Size of FET in use. The majorities of FET device in clinical use were 9 and $12 \mathrm{~cm}$ in length and 25, 27, $29 \mathrm{~mm}$ in diameter. B, Distal landing zone/level of FET. The landing levels of FET distal end were almost above the T8 level, except for 7 patients: T9 in 6 and T12 in 1 . FET, Frozen elephant trunk; $T$, thoracic vertebra.

$2.3 \%$ and $0 \% / 0 \%$ in paraplegia/paraparesis $(P=.062 /$ $.022)$. The durations of most surgical parameters, except for HCA, were longer for TARFET. In the PSM analysis, similar findings with smaller differences were observed.

Risk factor analysis for spinal cord injury. In TARFET, univariate and multivariate risk analyses for paraplegia or paraparesis demonstrated emergency or urgent surgery as an independent predictor for SCI, although FET length $12 \mathrm{~cm}$ or more and FET distal end below T8 level were not risk factors (Table 5).

\section{DISCUSSION}

In 2016, an article on a clinical trial of the presented FET device was published. ${ }^{20}$ This is the first official study of this FET device to demonstrate its impact on the early outcomes of TAR through the multicenter prospective comparative study between TARFET and cTAR.

In the 1990s, the original idea of "open-style sent-graft placement" was developed by Kato and colleagues. ${ }^{14}$ Since then, a part of open arch repairs was shifted to this lessinvasive approach using homemade stent grafts. ${ }^{14-18}$ With this technique, even for extensive arch lesions connecting downstream to the mid-descending aorta, a 1-stage repair was feasible. However, the initial Japanese experience demonstrated a high incidence of SCI because of long coverage of the responsible segmental arteries to the spinal cord perfusion or to embolization of clot, atheroma, or air into these arteries. ${ }^{17-19,29}$ Compared with 2-stage procedures of the cTAR followed by endografting, a higher risk of SCI in TARFET was demonstrated. ${ }^{32}$ 
TABLE 3. Comparison in acute aortic dissection

\begin{tabular}{|c|c|c|c|c|c|c|c|c|}
\hline \multirow{2}{*}{\multicolumn{2}{|c|}{ Variables/parameters/outcome }} & \multicolumn{3}{|c|}{ Unadjusted dataset } & \multicolumn{3}{|c|}{ PSM adjusted dataset (1-11) } & \multirow[b]{2}{*}{ SMD } \\
\hline & & TARFET $(n=154)$ & $\operatorname{cTAR}(n=60)$ & $P$ & TARFET $(n=42)$ & cTAR $(n=42)$ & $P$ & \\
\hline \multicolumn{2}{|c|}{ 1. Age, mean $\pm \mathrm{SD}$} & $61.1 \pm 11.0$ & $60.2 \pm 13.9$ & .60 & $60.6 \pm 11.6$ & $59.7 \pm 12.6$ & .726 & 0.07 \\
\hline \multicolumn{2}{|c|}{ 2. Male gender, $\mathrm{n}(\%)$} & $106(68.8)$ & $40(66.7)$ & .76 & $29(69.1)$ & $28(66.7)$ & .815 & 0.05 \\
\hline \multicolumn{9}{|c|}{ Preoperative conditions } \\
\hline \multirow{2}{*}{\multicolumn{2}{|c|}{$\begin{array}{l}\text { 3. Stanford type A, n (\%) } \\
\text { Shock/CPA, n (\%) }\end{array}$}} & $146(94.8)$ & $59(98.3)$ & .25 & $42(100)$ & $42(100)$ & - & - \\
\hline & & $17(11.0)$ & $5(8.3)$ & .558 & $5(11.9)$ & 5 (11.9) & 1.00 & 0.00 \\
\hline \multicolumn{2}{|c|}{ 4. Neurologic symptom, n (\%) } & $2(1.3)$ & $0(0)$ & .38 & $0(0)$ & $0(0)$ & - & - \\
\hline \multicolumn{2}{|c|}{ 5. Other organ malperfusion, $\mathrm{n}(\%)$} & $19(12.3)$ & $0(0)$ & $.004 *$ & $0(0)$ & $0(0)$ & - & - \\
\hline & $133(86.4)$ & $53(88.3)$ & .52 & $37(88.1)$ & $38(90.5)$ & .545 & 0.07 \\
\hline \multicolumn{2}{|c|}{ Urgent, n (\%) } & $7(4.5)$ & $4(6.7)$ & & $2(4.8)$ & $3(7.1)$ & & \\
\hline \multicolumn{2}{|c|}{ Elective, n (\%) } & $14(9.1)$ & $3(5.0)$ & & $3(7.1)$ & $1(2.4)$ & & \\
\hline \multicolumn{2}{|l|}{ 7. Redo, n (\%) } & $2(1.3)$ & $1(1.7)$ & .84 & $0(0)$ & $0(0)$ & - & - \\
\hline \multicolumn{9}{|c|}{ Preoperative status/coexisting } \\
\hline \multicolumn{2}{|c|}{ Cerebrovascular disease, $\mathrm{n}(\%)$} & $13(8.4)$ & $5(8.3)$ & .98 & $4(9.5)$ & $3(7.1)$ & .693 & 0.08 \\
\hline \multicolumn{2}{|l|}{ 8. CKD, n (\%) } & $39(25.3)$ & $19(31.7)$ & .35 & $13(31.0)$ & $12(28.6)$ & .811 & 0.05 \\
\hline \multicolumn{2}{|c|}{ 9. Hemodialysis, n (\%) } & $5(3.3)$ & $0(0)$ & .16 & $0(0)$ & $0(0)$ & - & - \\
\hline \multicolumn{2}{|c|}{ 10. COPD, n (\%) } & $6(3.9)$ & $3(5.0)$ & .73 & $2(4.8)$ & $1(2.8)$ & .557 & 0.12 \\
\hline \multirow{2}{*}{\multicolumn{2}{|c|}{$\begin{array}{l}\text { 11. Japan score, mean } \pm \text { SD } \\
\text { CSFD, n }(\%)\end{array}$}} & $11.9 \pm 10.3$ & $9.1 \pm 8.3$ & .30 & $10.2 \pm 10.3$ & $9.3 \pm 8.6$ & .65 & 0.09 \\
\hline & & $4(2.6)$ & $0(0)$ & .21 & $4(9.5)$ & $3(7.1)$ & .693 & 0.08 \\
\hline \multicolumn{2}{|c|}{ Operation (min), mean $\pm \mathrm{SD}$} & $465.6 \pm 132.6$ & $461.5 \pm 170.5$ & .85 & $461.8 \pm 134.9$ & $468.9 \pm 169.6$ & .83 & 0.04 \\
\hline \multicolumn{2}{|c|}{$\mathrm{CPB}(\min )$, mean $\pm \mathrm{SD}$} & $241.2 \pm 71.9$ & $253.5 \pm 103.3$ & .32 & $241.5 \pm 89.4$ & $260.5 \pm 107.2$ & .38 & 0.19 \\
\hline \multicolumn{2}{|c|}{$\mathrm{SCP}(\min )$, mean $\pm \mathrm{SD}$} & $140.8 \pm 48.1$ & $160.7 \pm 90.6$ & .069 & $135.1 \pm 46.4(\mathrm{n}=33)$ & $168.5 \pm 94.8(\mathrm{n}=31)$ & .08 & 0.44 \\
\hline Myocardial isch & $(\min )$, mean $\pm \mathrm{SD}$ & $135.6 \pm 56.1$ & $130.8 \pm 75.5$ & .61 & $136.4 \pm 64.5$ & $120.7 \pm 79.1$ & .32 & 0.21 \\
\hline $\mathrm{HCA}(\mathrm{min}), \mathrm{me}$ & SD & $51.2 \pm 22.0$ & $62.7 \pm 27.7$ & $.002 *$ & $49.8 \pm 17.8$ & $64.2 \pm 30.2$ & $.009 *$ & 0.58 \\
\hline Root replaceme & $(\%)$ & $2(1.3)$ & $2(3.3)$ & .32 & $1(2.4)$ & $1(2.4)$ & 1.00 & 0.00 \\
\hline Other surgical $\mathrm{p}$ & dures, $\mathrm{n}(\%)$ & $16(10.4)$ & $5(8.3)$ & .65 & $2(4.8)$ & $3(7.1)$ & .645 & 0.09 \\
\hline $\mathrm{ET}, \mathrm{n}(\%)$ & & - & $31(50.8)$ & - & - & $19(45.2 \%)$ & - & - \\
\hline ICU stay $(d), m$ & (IQR) & $5(4-8)$ & $5(3-8)$ & .94 & $4(3-7)$ & $5(4-8)$ & .14 & 0.11 \\
\hline Hospital stay (d & dian (IQR) & $28(22-39)$ & $28(18.5-36)$ & .32 & $25.5(21-34)$ & $28(19-35)$ & .86 & 0.10 \\
\hline 30-d mortality, 1 & & $2(1.3)$ & $0(0)$ & .38 & $1(2.4)$ & $0(0)$ & .31 & 0.21 \\
\hline In-hospital mort & $\mathrm{n}(\%)$ & $3(1.9)$ & $0(0)$ & .28 & $1(2.4)$ & $0(0)$ & .31 & 0.21 \\
\hline Major morbiditi & & & & & & & & \\
\hline Brain $\dagger$ & total, $\mathrm{n}(\%)$ & $20(13.0)$ & 7 (11.7) & .79 & $2(4.8)$ & $6(14.3)$ & .14 & 0.32 \\
\hline & temporary, $\mathrm{n}(\%)$ & $8(5.2)$ & $6(10.0)$ & .2 & $2(4.8)$ & $5(11.9)$ & .24 & 0.25 \\
\hline & permanent, n (\%) & $12(7.8)$ & $1(1.7)$ & .092 & $0(0)$ & $1(2.4)$ & .31 & 0.21 \\
\hline Spinal cord $\dagger$ & total, $\mathrm{n}(\%)$ & $6(3.9)$ & $0(0)$ & .12 & $1(2.4)$ & $0(0)$ & .31 & 0.21 \\
\hline & paraplegia, n (\%) & $4(2.6)$ & $0(0)$ & .21 & $0(0)$ & $0(0)$ & - & - \\
\hline & paraparesis, n (\%) & $2(1.3)$ & $0(0)$ & .38 & $1(2.4)$ & $0(0)$ & .31 & 0.21 \\
\hline Heart, n (\%) & & $4(2.6)$ & $2(3.3)$ & .77 & $2(6.1)$ & $2(4.8)$ & .31 & 0.21 \\
\hline Lung, n (\%) & & $34(22.1)$ & $10(16.7)$ & .38 & $11(33.3)$ & $10(23.8)$ & .56 & 0.12 \\
\hline Kidney, n (\%) & & $15(9.7)$ & $4(6.7)$ & .48 & $6(18.2)$ & $4(9.5)$ & .595 & 0.11 \\
\hline Bleeding, $\mathrm{n}(\%)$ & & $41(26.6)$ & $14(23.3)$ & .62 & $6(18.2)$ & $16(38.1)$ & .693 & 0.08 \\
\hline Infection, $\mathrm{n}(\%)$ & & $2(1.3)$ & $1(1.7)$ & .27 & $0(0)$ & $1(2.4)$ & .243 & 0.25 \\
\hline
\end{tabular}

PSM, Propensity score matching; TARFET, total arch replacement with frozen elephant trunk, $C T A R$, conventional TAR; $S M D$, standardized mean difference; $S D$, standard deviation; $C P A$, cardiopulmonary arrest; $C K D$, chronic kidney disease; $C P B$, cardiopulmonary bypass; $C O P D$, chronic obstructive pulmonary disease; $C S F D$, cerebrospinal fluid drainage; $S C P$, selective cerebral perfusion; $H C A$, hypothermic circulatory arrest; $E T$, elephant trunk; $I C U$, intensive care unit; $I Q R$, interquartile range. *Significantly different. $\dagger$ ¡onferroni correction was applied. 
TABLE 4. Comparison in aneurysm

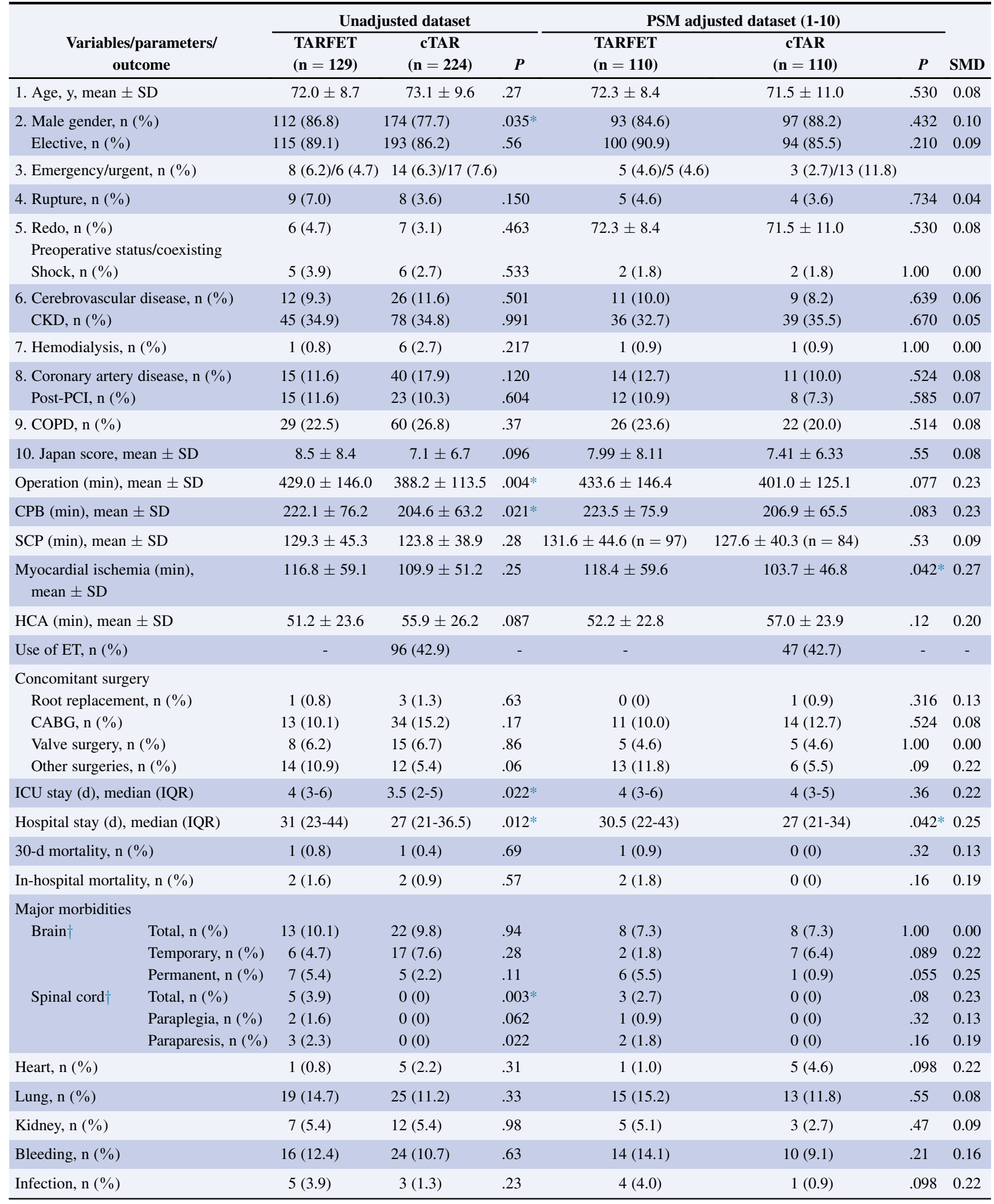

PSM, Propensity score matching; TARFET, total arch replacement with frozen elephant trunk; $c T A R$, conventional TAR; SMD, standardized mean difference; SD, standard deviation; $C K D$, chronic kidney disease; $P C I$, percutaneous coronary intervention; $C O P D$, chronic obstructive pulmonary disease; $C P B$, cardiopulmonary bypass; $S C P$, selective cerebral perfusion; $H C A$, hypothermic circulatory arrest; $E T$, elephant trunk; $C A B G$, coronary artery bypass grafting; $I C U$, intensive care unit; $I Q R$, interquartile range. *Significant difference. †Bonferroni correction was applied. 
TABLE 5. Univariate and multivariate risk analyses for paraplegia or paraparesis

\begin{tabular}{|c|c|c|c|c|}
\hline \multirow[b]{2}{*}{ Variables } & \multicolumn{2}{|c|}{ Univariate analysis } & \multicolumn{2}{|c|}{ Multivariate analysis } \\
\hline & OR $(95 \%$ CI $)$ & $P$ & OR $(95 \%$ CI $)$ & $\boldsymbol{P}$ \\
\hline Age & $0.988(0.938-1.040)$ & .645 & - & - \\
\hline $\mathrm{AD}$ & $0.855(0.274-2.670)$ & .788 & - & - \\
\hline Emergency/urgent surgery & $4.423(1.197-16.345)$ & .026 & $4.348(1.174-16.103)$ & $.028 *$ \\
\hline Leg malperfusion & $2.035(0.247-16.772)$ & .509 & - & - \\
\hline CKD & $1.380(0.441-4.312)$ & .580 & - & - \\
\hline FET length $\geqq 12 \mathrm{~cm}$ & $1.632(0.537-4.955)$ & .388 & - & - \\
\hline FET distal end below T8 level & $1.510(0.403-5.654)$ & .541 & - & - \\
\hline $\mathrm{HCA} \geqq 60 \mathrm{~min}$ & $2.104(0.692-6.395)$ & .190 & $2.035(0.663-6.245)$ & .214 \\
\hline Lowest temperature $\geqq 25^{\circ} \mathrm{C}$ & $1.069(0.352-3.244)$ & .907 & - & - \\
\hline
\end{tabular}

Lowest temperature: the lowest bladder/rectal temperature. $O R$, Odds ratio; $C I$, confidence interval; $A D$, aortic dissection; $C K D$, chronic kidney disease; $F E T$, frozen elephant trunk; $T$, thoracic vertebra; $H C A$, hypothermic circulatory arrest. *Independent risk factor for paraplegia or paraparesis.

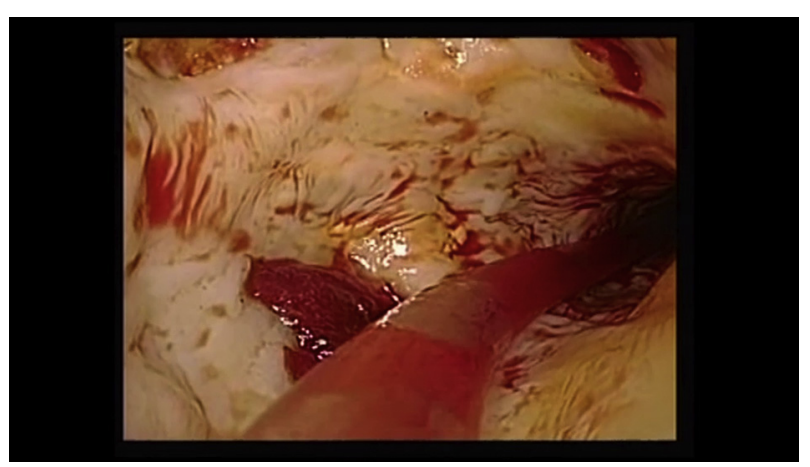

VIDEO 1. The patient is a 75-year-old man with a distal arch aneurysm of $55 \mathrm{~mm}$ in size complicated with chronic type B AD. The aortic arch was approached through a partial upper sternotomy with a $10-\mathrm{cm}$ skin incision. An 8-mm side-graft was anastomosed to the left axillary artery for arterial perfusion for $\mathrm{CPB}$ and, if necessary, for further extra-anatomic reconstruction of the LSCA. CPB was established with ascending aortic cannulation and right atrium venous drainage. After left ventricular venting through the left upper pulmonary vein, the patient was cooled to a bladder temperature of $28^{\circ} \mathrm{C}$. At the bladder temperature of $28^{\circ} \mathrm{C}$, HCA was induced with the central venous pressure elevated with a head-down position. The ascending aorta was crossclamped, and antegrade cardioplegia was induced for cardiac arrest. The transverse arch was incised and antegrade SCP was established with a $12 \mathrm{~F}$ or $15 \mathrm{~F}$ balloon-tipped cannula inserted into each arch vessel. The SCP was carried out with the flow of 700 to $900 \mathrm{~mL} / \mathrm{min}$ $(10-12 \mathrm{~mL} / \mathrm{kg} / \mathrm{min})$ at $23^{\circ} \mathrm{C}$, maintaining the systemic arterial pressure/ balloon-tip pressure between 30 and $50 \mathrm{~mm} \mathrm{Hg}$. The arch was divided at the zone 2 level between the LCCA and the LSCA. The LSCA was transected, and its proximal end was closed with a continuous suture of 4-0 polypropylene. The endoscopy was inserted into the descending aorta and the inside conditions including the distal landing zone for FET were assessed. The primary entry of type B AD had already closed. The distance between the proximal FET fixation site and the distal landing zone was estimated for decision making of the FET length. In this case, on the multiplanar reformation image of preoperative CT scans, it was decided to be $12 \mathrm{~cm}$ in length and $33 \mathrm{~mm}$ in diameter. With the endoscopic guidance, the FET was inserted into the descending aorta carefully and deployed with retro-
Alternatively, the cTAR using a multibranched arch graft has been well standardized with secured brain protection of SCP and RCP, ${ }^{21-28}$ which was performed for approximately 4000 cases in 2016 based on the annual report of the Japanese Association for Thoracic Surgery analyzing the Japan Adult Cardiovascular Surgery Database (JCVSD). ${ }^{33}$ The outcomes were favorable with in-hospital mortality of $11.3 \%$ and $3.4 \%$ for acute and chronic type A ADs, and of $4.8 \%$ and $16.9 \%$ in nonruptured and ruptured aneurysms. Another report on the neurologic complications from the JCVSD in 2015 and 2016 demonstrated stroke rates of $11.3 \%$ in acute and $5.0 \%$ in chronic ADs and of $6.3 \%$ and $13.6 \%$ in nonruptured and ruptured aneurysms. ${ }^{34}$ Compared with these results, the J-ORCHESTRA study

grade femoral artery perfusion to prevent embolization during deployment of the FET. The nonstented part of FET was transected and trimmed at the same level of the aortic stump. The proximal nonstented end of FET was fixed roughly to the aortic stump with 4 mattress sutures of 4-0 polypropylene. The multi-branched arch prosthesis of $26 \mathrm{~mm}$ was selected and connected with 4 mattress sutures of 4-0 polypropylene. The sutures were tied down, and the distal anastomosis was completed with continuous over and over sutures of 4-0 polypropylene. After deairing, the systemic perfusion was restarted with a side-branch of the arch prosthesis. Rewarming was commenced. The LSCA was reconstructed with the interposition of a 10-mm graft because the anastomosis was difficult because of the limited surgical field in the zone 2 procedure. At the proximal site, the aortic stump was trimmed just above the sinotubular junction. The arch graft was anastomosed with a continuous over and over suture of 4-0 polypropylene with the outside felt reinforcement. Finally, the other arch vessels of the LCCA and the brachiocephalic artery were reconstructed with 5-0 polypropylene sutures. The postoperative CT scans demonstrated no remarkable abnormal findings with a nearly proper position of FET. However, the distal end of FET was located in the end of curved segment between the arch and descending aorta, a $15 \mathrm{~cm}$ FET device might be more appropriate, in particular, for the late outcome without aortic events. On this, further investigations are required. Video available at: https://www.jtcvs.org/article/S00225223(21)00560-2/fulltext. 
demonstrated a more favorable outcome for cTAR with lower rates of 30-day and in-hospital mortality $(0.6 \%$ and $0.9 \%$ ) and with stroke in $2.5 \%$ and paraplegia in $0 \%$.

On the other hand, in Europe and China, the new trend toward FET was developed with recent advances in endografting repairs. ${ }^{3-13}$ Many articles on TARFET have been published with the development of factory-made devices. Worldwide discussions on FET have been focused on the following issues: how to use TARFET, which aortic pathologies fit, and whether the procedure is useful or harmful.

Along with this trend, the new FET device became clinically available in Japan in $2014 .{ }^{20}$ Its advantages consist of size variations, simple design of FET and delivery system, easy insertion, easy adjustment of its position, gentler dilatation, and easy distal anastomosis of TAR due to its size variations and simple design. ${ }^{20}$ Furthermore, this device has an inside stent, which would reduce potential injury of the aortic flap or wall. It also has a structure such that its wire top hardly protrudes inward when it is bent. As far as disadvantages, this device with a single wire inside stent has stronger spring back force than separate stent ones, which may cause aortic wall or flap injury. Another is the requirement of an additional arch prosthesis for TAR, apart from other European devices. However, the simple design without multi-branches is rather one of the benefits, which allows us to insert it easily, to check the FET conditions clearly after its deployment, and to easily adjust the distance between the third branch for the LSCA and the TAR distal anastomosis.

In this study, the outcome of TARFET was acceptable for higher-risk patients and difficult emergency or redo surgeries. However, its higher rates of neurologic morbidities were found compared with cTAR. The surgical parameters were also longer, except for the HCA time. Even in the PSM analyses, the results were similar, although the differences became smaller. In the following differential analyses on acute $\mathrm{AD}$ and aneurysm, there were no significant differences, although the outcomes were relatively worse. On the whole, the results of TARFET were slightly worse compared with those of cTAR. It was due to the higher preoperative risk scores (Japan score) estimated with the data of the JCVSD, ${ }^{35}$ which were based on the higher incidences of acute $\mathrm{AD}$ and redo surgery. The incidence of other malperfusion was also higher. Another reason was the excellent outcome of cTAR with less mortality and neurologic morbidity. From Japan, satisfactory outcomes were reported in the larger series of cTAR including 423 and 1005 patients, respectively. ${ }^{26,27}$ Even in these highvolume aortic centers, the rates of in-hospital mortality, stroke, and paraplegia were $4.5 \%$ and $5.2 \%, 3.3 \%$, and $3.6 \%$, and $0.9 \%$, and $0 \%$, respectively. In the nationwide analyses, the incidences of in-hospital mortality, stroke, and paraplegia were $7.8 \%, 8.4 \%$, and $2.4 \%$ for cTAR, respectively. ${ }^{33}$ Compared with these results, the outcome for TEAFET with an in-hospital mortality rate in $1.9 \%$, stroke in $5.6 \%$, and paraplegia in $1.6 \%$ was comparable or more favorable. Furthermore, it was superior to those of the other series. ${ }^{3-13}$ In a position paper by the EACTS Vascular Domain, the aggregated morbidity and mortality rates were described as in-hospital mortality in $1.8 \%$ to $17.2 \%$, stroke in $2.5 \%$ to $20 \%$, and SCI in $0 \%$ to $21 \%$. ${ }^{9}$ Another meta-analysis reported in-hospital mortality in $8.8 \%(0 \%-40.9 \%)$, stroke in $7.6 \%(0 \%-24 \%)$, and paraplegia in $4.7 \%(0 \%-21.6 \%) .{ }^{19}$ In the preceding clinical trial on this FET device among 9 major centers, the rates of in-hospital mortality, stroke, and paraplegia were $5.1 \%, 10.0 \%$, and $1.7 \%$, respectively. ${ }^{20}$ The outcome for TARFET in this study of the second largest patient number was acceptable, even though more emergency or redo surgeries were included.

With regard to neurologic complications, the incidence of stroke was higher for TARFET, presumably due to a higher prevalence of acute $\mathrm{AD}$, preoperative shock, brain malperfusion, and emergency or redo surgery. In particular, paraplegia occurred only in TARFET. The risk analyses demonstrated only emergency or urgent surgery as an independent predictor for SCI However, for spinal safety, use of longer FET devices, deeper FET insertion below the T8 level, and HCA over 60 minutes at moderate hypothermia should be avoided. ${ }^{20,29}$ Furthermore, another caution should be taken for the LSCA perfusion in the SCP and for its gentle deployment with retrograde femoral artery perfusion to prevent emboli of debris and air into the ICAs. ${ }^{29}$ In this study, perioperative CSFD was performed in only 8 patients. In emergency settings, it is extremely difficult. In elective cases with a high-risk for SCI, CSFD should be considered to reduce the risk for SCI.

\section{Study Limitations}

There are certain limitations. First, 41 institutions participated. Second, the patient numbers varied from 1 to 63 at each center. Third, the ratios of TARFET and cTAR were different, because the procedure selection was nonrandomized, depending on the strategies of each institute. Fourth, the balances of disease distribution were different. Fifth, the experiences with TARFET and cTAR varied. Sixth, there was a patient selection bias for prospective study requiring informed consent from the patient or family preoperatively. Extremely critical patients with deep shock, cardiac arrest, or deep coma might have been excluded. However, this study demonstrated a "real-world" glimpse of TAR procedures, including TARFET in Japan.

To address the precise impact of TARFET, it is necessary to investigate the long-term outcome, including analyses of findings of follow-up computed tomography scans and medical cost. The study remains ongoing, with data being collected from each institution. We will provide an updated report in the near future. 


\section{Comparative study of Japanese frozen elephant trunk device for open aortic arch repairs}
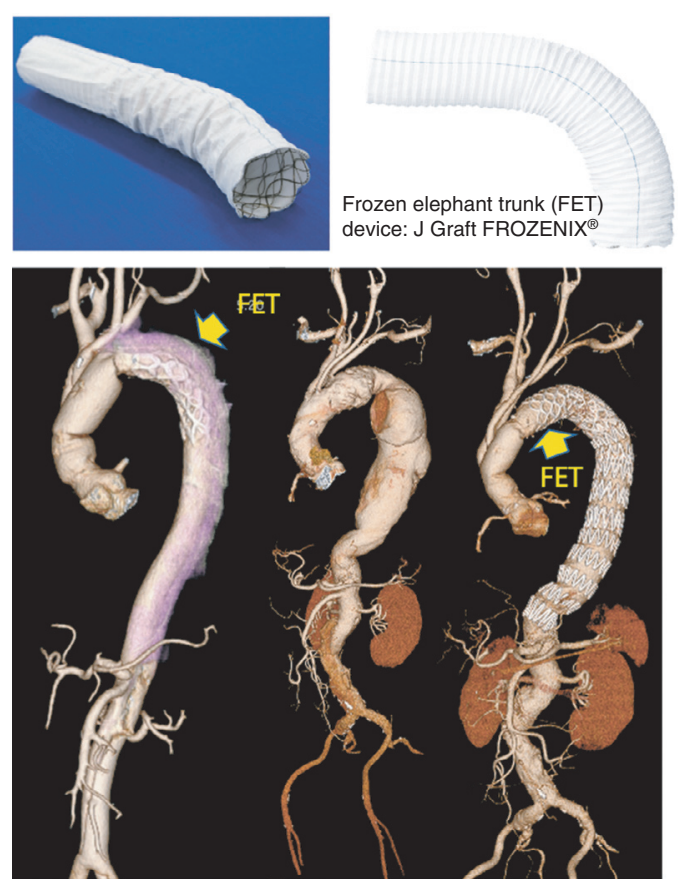

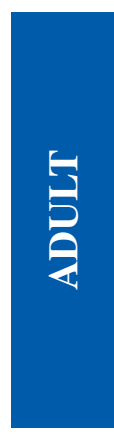

FIGURE 3. Graphical abstract showing a summary of this study. TARFET, Total arch replacement with frozen elephant trunk; $c$ TAR, conventional total arch replacement; pts, patients. *Significantly different.

\section{CONCLUSIONS}

TARFET was applied more to acute AD, and the outcome was acceptable despite its higher prevalence of emergency or redo surgery, which was comparable to that of wellstandardized cTAR. TARFET had higher rates of SCI than cTAR, and it is a disadvantage of this approach (Figure 3).

\section{Conflict of Interest Statement}

Dr Ogino, Dr Kato, Dr Shimizu, Dr Minatoya, and Dr Yamanaka serve as medical advisers for Japan Lifeline Co, Ltd. All other authors reported no conflicts of interest.

The Journal policy requires editors and reviewers to disclose conflicts of interest and to decline handling or reviewing manuscripts for which they may have a conflict of interest. The editors and reviewers of this article have no conflicts of interest.

The authors thank the participating institutions for providing data. This study was funded by Japan Lifeline Co, Ltd. However, the data collection and analyses were independently performed, and the findings in this manuscript are solely those of the J-ORCHESTRA study investigators, which do not belong to Japan Lifeline Co, Ltd.

\section{References}

1. Borst HG, Walterbusch G, Schaps D. Extensive aortic replacement using "elephant trunk" prosthesis. Thorac Cardiovasc Surg. 1983;31:37-40.
2. Karck M, Chavan A, Hagl C, Friedrich H, Galanski M, Haverich Axel. The frozen elephant trunk technique: a new treatment for thoracic aortic aneurysms. Thorac Cardiovasc Surg. 2003;125:1550-3.

3. Di Bartolomeo R, Pacini D, Savini C, Pilato E, Martin-Suarez S, Di Marco L, et al. Complex thoracic aortic disease: single-stage procedure with the frozen elephant trunk technique. J Thorac Cardiovasc Surg. 2010;140:S81-5.

4. Tsagakis K, Pacini D, Di Bartolomeo R, Gorlitser M, Weiss G, Grabenwoger M, et al. Multicenter early experience with extended aortic repair in acute aortic dissection: is simultaneous descending stent grafting justified? J Thorac Cardiovasc Surg. 2010;140:S116-20.

5. Pacini D, Tsagakis K, Jakob H, Mestres CA, Armaro A, Eiss G, et al. The frozen elephant trunk for the treatment of chronic dissection of the thoracic aorta: a multicenter experience. Ann Thorac Surg. 2011;92:1663-70.

6. Sun L, Li M, Zhu J, Lu Y, Chang Q, Zheung J, et al. Surgery for patients with Marfan syndrome with type A dissection involving the aortic arch using total arch replacement combined with stented elephant trunk implantation: the acute versus the chronic. J Thorac Cardiovasc Surg. 2011;142:e85-91.

7. Mestres CA, Tsagakis K, Pacini D, Di-Bartolomeo R, Grabenwoger M, Borger $\mathrm{M}$, et al. One-stage repair in complex multisegmental thoracic aneurysmal disease: results of a multicenter study. Eur J Cardiothorac Surg. 2013; $1: 1-7$.

8. Shrestha M, Pichlmaier M, Martens A, Hagl C, Khaladj N, Haverich A. Total aortic arch replacement with a novel four-branched frozen elephant trunk graft: first-in-man results. Eur J Cardiothorac Surg. 2013;43:406-10.

9. Shrestha M, Bachet J, Bavaria J, Carrel TP, De Paulis R, Di Bartolomeo R, et al. Current status and recommendations for use of the frozen elephant trunk technique: a position paper by the Vascular Domain of EACTS. Eur J Cardiothorac Surg. 2015;47:759-69.

10. Shrestha M, Kaufeld T, Beckmann E, Fleissner F, Umminger J, Abd Alhadi F, et al. Total aortic arch replacement with a novel 4-branched frozen elephant trunk prosthesis: single-center results of the first 100 patients. J Thorac Cardiovasc Surg. 2016;152:148-59.e1.

11. Leontyev S, Tsagakis K, Pacini D, Di Bartolomeo R, Mohr FW, Weiss G, et al. Impact of clinical factors and surgical techniques on early outcome of patients treated with frozen elephant trunk technique by using EVITA open stent-graft: results of a multicentre study. Eur J Cardiothorac Surg. 2016;49:660-6. 
12. Roselli EE, Idrees JJ, Bakaeen FG, Tong MZ, Soltesz EG, Mick S, et al. Evolution of simplified frozen elephant trunk repair for acute DeBakey type I dissection: midterm outcomes. Ann Thorac Surg. 2018;105:749-55.

13. Jakob H, Moughal S, Bashir M. Frozen elephant trunk with straight vascular prosthesis: single-center experience with a review of current trends. J Cardiovasc Surg (Torino). 2020;61:301-7.

14. Kato M, Ohnishi K, Kaneko M, Ueda T, Kishi D, Mizushima T, et al. New graftimplanting method for thoracic aortic aneurysm or dissection with a stented graft. Circulation. 1996;94(Suppl II):II188-93.

15. Ishihara H, Uchida N, Yamasaki C, Sakashita M, Kanou M. Extensive primary repair of the thoracic aorta in Stanford type A acute aortic dissection by means of a synthetic vascular graft with a self-expandable stent. J Thorac Cardiovasc Surg. 2002;123:1035-40.

16. Uchida N, Shibamura H, Katayama A, Sutoh M, Kuraoka M, Ishihara H. Longterm results of the frozen elephant trunk technique for the extensive arteriosclerotic aneurysm. J Thorac Cardiovasc Surg. 2010;139:913-7.

17. Usui A, Fujimoto K, Ishiguchi T, Yoshikawa M, Akita T, Ueda Y. Cerebrospinal dysfunction after endovascular stent-grafting via a median sternotomy: the frozen elephant trunk procedure. Ann Thorac Surg. 2002;74:S1821-4; discussion S1825-32.

18. Flores J, Kunihara T, Shiiya N, Yoshimoto K, Matsuzaki K, Yasuda K. Extensive deployment of the stented elephant trunk is associated with an increased risk of spinal cord injury. J Thorac Cardiovasc Surg. 2006;131:336-42.

19. Preventza O, Liao JL, Olive JK, Simpson K, Critsinelis AC, Coselli JS, et al. Neurologic complications after the frozen elephant trunk procedure: a metaanalysis of more than 3000 patients. J Thorac Cardiovasc Surg. 2019;160: 20-33.e4.

20. Uchida N, Katayama A, Higashiue S, Shiono M, Hata M, Kato M, et al. A new device as an open stent graft for extended aortic repair: a multicenter early experience in Japan. Eur J Cardiothorac Surg. 2016;49:1270-8.

21. Ogino H, Sasaki H, Minatoya K, Matsuda H, Tanaka H, Kitamura S, et al. Evolving arch surgery using integrated antegrade selective cerebral perfusion: impact of axillary artery perfusion. J Thorac Cardiovasc Surg. 2008;136: 641-8; discussion 948-9.

22. Iba Y, Minatoya K, Matsuda H, Sasaki H, Tanaka H, Ogino H, et al. Contemporary open aortic arch repair with selective cerebral perfusion in the era of endovascular aortic repair. J Thorac Cardiovasc Surg. 2013;145(3 Suppl):S72-7.

23. Watanuki H, Ogino H, Minatoya K, Matsuda H, Sasaki H, Ando M, et al. Is emergency total arch replacement with a modified elephant trunk technique justified for acute type A aortic dissection? Ann Thorac Surg. 2007;84:1585-91.

24. Inoue Y, Matsuda H, Omura A, Seike Y, Uehara K, Sasaki H, et al. Comparative study of the frozen elephant trunk and classical elephant trunk techniques to supplement total arch replacement for acute type A aortic dissection. Eur J Cardiothorac Surg. 2019;56:579-86.
25. Kazui T, Yamashita K, Washiyama N, Terada H, Bashar AH, Suzuki T, et al. Usefulness of antegrade selective cerebral perfusion during aortic arch operations. Ann Thorac Surg. 2002;74:S1806-9; discussion S1825-32.

26. Okita Y, Okada K, Omura A, Kano H, Minami H, Inoue T, et al. Total arch replacement using antegrade cerebral perfusion. J Thorac Cardiovasc Surg. 2013;145(3 Suppl):S63-71.

27. Minatoya K, Inoue Y, Sasaki H, Tanaka H, Seike Y, Ogino H, et al. Total arch replacement using a 4-branched graft with antegrade cerebral perfusion. J Thorac Cardiovasc Surg. 2019; 157:1370-8.

28. Ueda Y, Miki S, Kusuhara K, Okita Y, Tahata T, Yamanaka K. Deep hypothermic systemic circulatory arrest and continuous retrograde cerebral perfusion for surgery of aortic arch aneurysm. Eur J Cardiothorac Surg. 1992;6:36-41; discussion 42.

29. Katayama K, Uchida N, Katayama A, Takahashi S, Takasaki T, Kurosaki T, et al. Multiple factors predict the risk of spinal cord injury after the frozen elephant trunk technique for extended thoracic aortic disease. Eur J Cardiothorac Surg. 2015;47:616-20.

30. Clark RE. Definitions of terms of the Society of Thoracic Surgeons National Cardiac Surgery database. Ann Thorac Surg. 1994;58:271-3.

31. Shroyer AL, Coombs LP, Peterson ED, Eiken MC, DeLong ER, Chen A, et al; Society of Thoracic Surgeons. The Society of Thoracic Surgeons: 30-day operative mortality and morbidity risk models. Ann Thorac Surg. 2003;75: 1856-64.

32. Kawaharada N, Kurimoto Y, Ito T, Koyanagi T, Yamauchi A, Nakamura M, et al. Hybrid treatment for aortic arch and proximal descending thoracic aneurysm: experience with stent grafting for second-stage elephant trunk repair. Eur J Cardiothorac Surg. 2009;36:956-61.

33. Committee for Scientific Affairs. The Japanese Association for Thoracic Surgery, correction to: thoracic and cardiovascular surgery in Japan in 2016: annual report by The Japanese Association for Thoracic Surgery. Gen Thorac Cardiovasc Surg. 2019;67:377-411.

34. Shimizu H, Hirahara N, Motomura N, Miyata H, Takamoto S. Current status of cardiovascular surgery in Japan, 2015 and 2016: analysis of data from Japan Cardiovascular Surgery database. 4-Thoracic aortic surgery. Gen Thorac Cardiovasc Surg. 2019;67:751-7.

35. Motomura N, Miyata H, Tsukihara H, Takamoto S. Risk model of thoracic aortic surgery in 4707 cases from a nationwide single-race population through a webbased data entry system: the first report of 30-day and 30-day operative outcome risk models for thoracic aortic surgery. Circulation. 2008;118:S153-9.

Key Words: aortic aneurysm, aortic dissection, early outcome, frozen elephant trunk, total arch replacement 


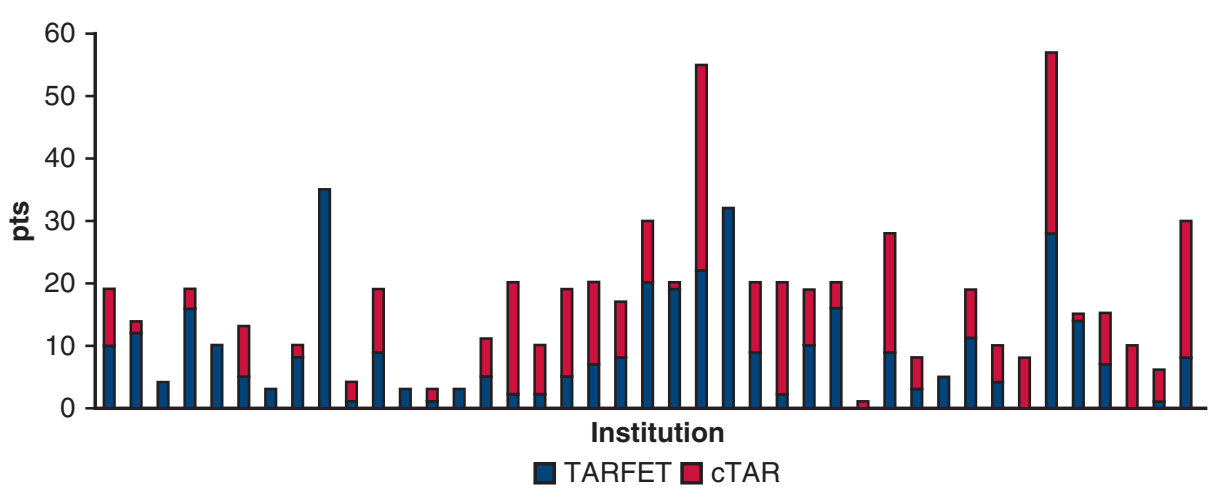

FIGURE E1. The number of enrolled patients from 41 institutions and the prevalence of procedures. TARFET, Total arch replacement with frozen elephant trunk; $c T A R$, conventional total arch replacement.

TARFET $(n=369)$

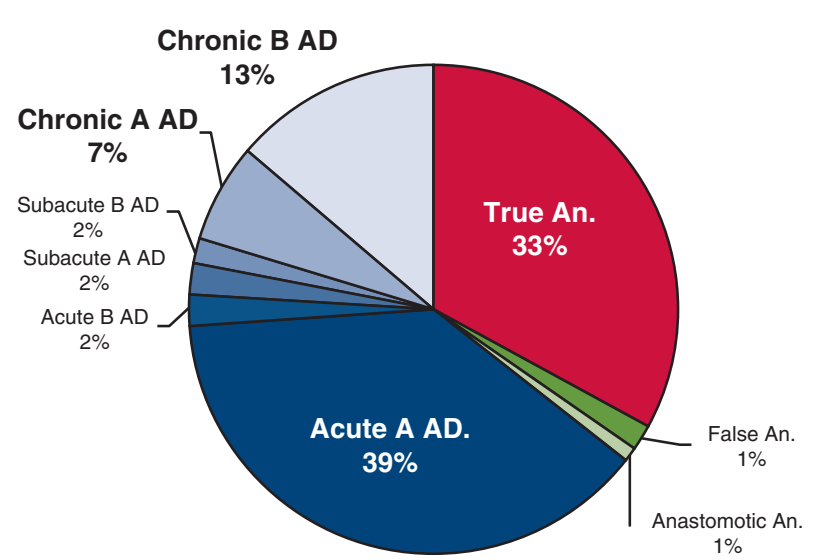

$\operatorname{CTAR}(n=315)$

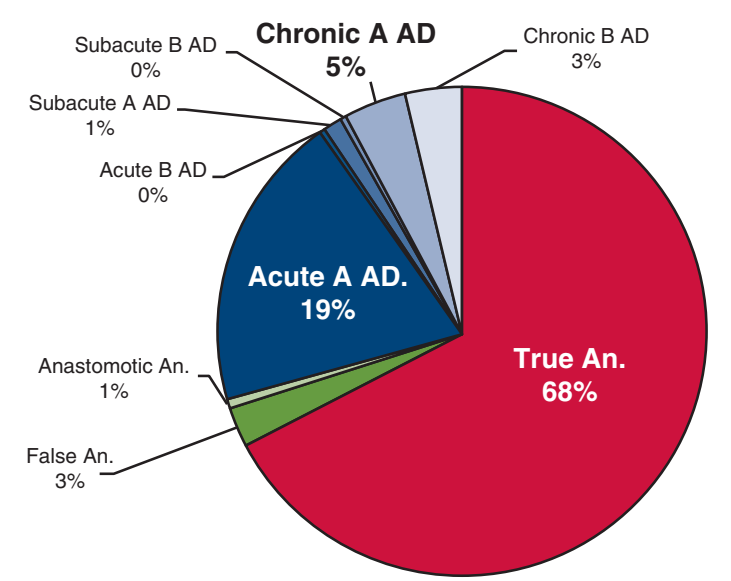

FIGURE E2. Aortic pathologies. TARFET, Total arch replacement with frozen elephant trunk; $c T A R$, conventional total arch replacement; $A / B$, Stanford type A/B; $A D$, aortic dissection; True An, nondissecting true aneurysm; An, Aneurysm. 
TABLE E1. Forty-one participating institutions in this study

\begin{tabular}{|c|c|}
\hline No & Institutions \\
\hline 1 & Kobe University Hospital \\
\hline 2 & Hokkaido University Hospital \\
\hline 3 & Asahikawa Medical University Hospital \\
\hline 4 & Hirosaki University Hospital \\
\hline 5 & Akita University Hospital \\
\hline 6 & Tohoku University Hospital \\
\hline 7 & Fukushima Medical University Hospital \\
\hline 8 & Southern Tohoku General Hospital \\
\hline 9 & Tokyo Medical University Hospital \\
\hline 10 & Keio University Hospital \\
\hline 11 & Mitsui Memorial Hospital \\
\hline 12 & Nihon University Hospital \\
\hline 13 & Showa University Toyosu Hospital \\
\hline 14 & Saitama Medical University International Medical Center \\
\hline 15 & Saitama Medical Center Jichi Medical University \\
\hline 16 & Sakakibara Heart Institute \\
\hline 17 & Yokohama City University Hospital \\
\hline 18 & Shinshu University Hospital \\
\hline 19 & Hamamatsu University Hospital \\
\hline 20 & Nagoya University Hospital \\
\hline 21 & Anjo Kosei Hospital \\
\hline 22 & Tenri Hospital \\
\hline 23 & National Cerebral and Cardiovascular Center Hospital \\
\hline 24 & Morinomiya Hospital \\
\hline 25 & Kishiwada Tokushukai Hospital \\
\hline 26 & Tokushima Red Cross Hospital \\
\hline 27 & Tottori University Hospital \\
\hline 28 & Tsuchiya General Hospital \\
\hline 29 & Hiroshima City Asa Hospital \\
\hline 30 & Fukuoka University Hospital \\
\hline 31 & Kurume University Hospital \\
\hline 32 & Saga University Hospital \\
\hline 33 & Oita University Hospital \\
\hline 34 & University of Miyazaki Hospital \\
\hline 35 & University of the Ryukyus Hospital \\
\hline 36 & Hyogo Brain and Heart Center \\
\hline 37 & Yamagata University Hospital \\
\hline 38 & Nihon University Itabashi Hospital \\
\hline 39 & Kyoto University Hospital \\
\hline 40 & Osaka City University Hospital \\
\hline 41 & Chiba-Nishi General Hospital \\
\hline
\end{tabular}

